\title{
Striatal ensembles continuously represent animals kinematics and limb movement dynamics during execution of a locomotor habit
}

\author{
Pavel E Rueda-Orozco*, David Robbe \\ From Twenty Second Annual Computational Neuroscience Meeting: CNS*2013 \\ Paris, France. 13-18 July 2013
}

The sensorimotor striatum contributes to the normal execution of motor habits but the mechanisms underlying this function are largely unknown[1]. Motor habits are stereotyped sequences of movements learned through a long trial-and-error process, automatically triggered by a set of sensory cues and that tend to persist despite outcome degradation (e.g. reward omission). We found that rats running on a treadmill become proficient in a fixed time interval estimation task by developing a highly stereotyped locomotor routine. Consistently with the definition of habits, the routine was acquired slowly (at least 2 months of daily practice), and once learned, it persisted for several sessions when the rewarding outcome was omitted. We took advantage of this unexpected behavior and used tetrode arrays to record the spiking activity of dorsolateral striatal ensembles while rats perform the locomotor habit. We report sequential activations of striatal neurons during the entire execution of the task. Importantly, we found that the firing rate of a large fraction of neurons was either locked to the locomotor limb movements or correlated with the kinematics of the habit (running speed, acceleration, position and time). These results contrast with the long-standing view that striatum is mainly concerned with action selection[2]. Rather movements and task kinematics encoding suggest that the striatum continuously control the execution of habitual action. Additional experiments are currently being performed to further investigate this hypothesis.

\footnotetext{
Acknowledgements

This work was funded by a Marie Curie International Reintegration Grant (IRG 230976, to DR). D.R. was supported by a Ramon-Y-Cajal fellowship from the spansih Ministerio de Ciencia e Innovación and the Avenir program from

* Correspondence: pavel.rueda@inserm.fr

INSERM, U901; Aix-Marseille University, UMR 901; INMED, France
}

INSERM. P.R.-O. was supported by a Marie Curie International Incoming Fellowship (IIF253873) and CONACyT, México.

Published: 8 July 2013

\section{References}

1. Redgrave $P$, Rodriguez $M$, Smith $Y$, Rodriguez-Oroz $M C$, Lehericy $S$, Bergman H, Agid Y, DeLong MR, Obeso JA: Goal-directed and habitual control in the basal ganglia: implications for Parkinson's disease. Nat Rev Neurosci 2010, 11:760-772.

2. Calabresi P, Di Filippo M: Neuroscience: Brain's traffic lights. Nature 2010, 466:449.

\section{doi:10.1186/1471-2202-14-S1-P325}

Cite this article as: Rueda-Orozco and Robbe: Striatal ensembles continuously represent animals kinematics and limb movement dynamics during execution of a locomotor habit. BMC Neuroscience 2013 14(Suppl 1):P325.
Submit your next manuscript to BioMed Central and take full advantage of:

- Convenient online submission

- Thorough peer review

- No space constraints or color figure charges

- Immediate publication on acceptance

- Inclusion in PubMed, CAS, Scopus and Google Scholar

- Research which is freely available for redistribution
C Biomed Central

\section{()

